\title{
The auditory recency advantage in longer term free recall is not enhanced by recalling prerecency items first
}

\author{
JOHN M. GARDINER and MARGARET M. GARDINER \\ The City University, London, England \\ and \\ VERNON H. GREGG \\ Birkbeck College, University of London, London, England
}

\begin{abstract}
Gardiner and Gregg (1979) showed that in a free-recall paradigm in which each list word is embedded in a continuous stream of subject-vocalized distractor activity, recency recall was greater when the words were presented auditorily rather than visually. The experiment described here showed that this auditory advantage persisted even when list and distractor items were both spoken at a controlled pace by the experimenter, and that it was little influenced by instructions to give priority in recall either to the beginning or to the end of the list. These results strengthen the conclusion that this effect cannot be accommodated by any echoic memory theory and, because the effect was not enhanced when prerecency items were recalled first, demonstrate an additional difference between it and the somewhat similar auditory advantage found in immediate recall.
\end{abstract}

The recency effect in immediate recall is greater if the items in a list are spoken rather than written, and it has been widely accepted that this auditory advantage arises from echoic memory (e.g., Broadbent, Vines, \& Broadbent, 1978; Crowder, 1976; Crowder \& Morton, 1969; O. C. Watkins \& M. J. Watkins, 1980). Echoic memory interpretations depend critically on evidence that auditory, but not visual, recency is vulnerable to interference from subsequent auditory input, and, of course, such modality-specific interference effects are well documented. However, evidence that seems to be incompatible with any echoic memory theory is now accumulating from a number of sources (for a recent review, see Gardiner, 1983). For example, there is now evidence that auditory and visual input may be functionally equivalent when the visual input entails lipreading (e.g., Campbell \& Dodd, 1980; Gardiner, Gathercole, \& Gregg, 1983; Spoehr \& Corin, 1978). There is also evidence, in a study by Gardiner \& Gregg (1979), of an auditory advantage in the longer term free-recall paradigm of Tzeng (1973; also see Bjork \& Whitten, 1974), that is, when a spoken distractor task occurs before and after the presentation of every single word in the list. The present study was empirically and methodologically oriented, and it was concerned with this last finding.

This research was supported by a grant from the Social Science Research Council. Requests for reprints may be sent to John M. Gardiner, Psychology Division, The City University, Northampton Square, London EC1V 0HB, England.
The finding had not been anticipated either on theoretical or on empirical grounds, because, in accord with echoic memory interpretations, the same distractor task had been shown to remove the auditory advantage when the task occurred only after all the words in the list had been presented (Gardiner, Thompson, \& Maskarinec, 1974; also see Broadbent et al., 1978, and Martin \& Jones, 1979). In several tests of its generality, however, Gardiner and Gregg (1979) failed to discover any boundary conditions of the longer term auditory advantage, and they obtained no evidence that that effect differed in any other respects from the more familiar immediate-recall effect. In immediate recall, there are only two variables for which some influence upon the auditory advantage seems firmly established. One of these variables is phonological similarity among the list items, which is known to sharply reduce, if not eliminate, the immediate-recall effect (see, e.g., M. J. Watkins, O. C. Watkins, \& Crowder, 1974); the possible influence of this variable on the longer term effect is the subject of another, forthcoming study (Gregg \& Gardiner, in press). The other variable is the instructions with regard to the order of recall.

There are three immediate-recall studies that have examined the effect of order-of-recall instructions on the auditory advantage. Craik (1969), using modified freerecall instructions, and Madigan (1971), using forwardor backward-serial-order recall instructions, found that when recall starts from the beginning of the list, recency recall is reduced but the auditory advantage is greatly enhanced. And Nilsson, Wright, and Murdock (1979) 
found a similar pattern of results with instructions to recall words near the end of the list first, in either a forward or a backward order, although, not surprisingly, their effect was much less pronounced. The major purpose of the present study was to investigate the effect of instructions to start recall from the beginning, rather than from the end, of the list on the auditory advantage in the distractor paradigm and so provide a further convergent test with respect to the immediate- and longer term recall effects. The question at hand was whether the auditory advantage in longer term recall is similarly enhanced when prerecency items are recalled first.

A further aim of the present study was to replicate the longer term effect under more rigorously controlled conditions. In Gardiner and Gregg's (1979) study, list items had been spoken at the time of presentation by the experimenter or presented for subject vocalization manually via decks of cards. Distractor items had also been presented on cards for a self-paced counting task: counting aloud backward by threes from a given number. And order of recall was controlled only insofar as subjects were advised that they would find it helpful to try to recall the last words in each list first. So, in the following experiments, not only were the subjects instructed to recall items from either the later or the earlier part of the list first (cf. Craik, 1969), but also both distractor and list items were prerecorded. Otherwise, the procedure was comparable to that used in the later experiments by Gardiner and Gregg (1979), including the use of a list length of only six words and a shortened, 10 sec period of interspersed distraction.

\section{METHOD}

\section{Subjects}

Thirty-two undergraduate students at The City University were tested individually. They were paid for their services.

\section{Design}

The experimental design was completely within-subjects, with list modality (auditory or visual), recall instructions ("end" or "beginning"), and serial position as the principal independent variables.

All subjects were presented with a total of 20 experimental lists, with six words in each. Ten lists were presented auditorily and 10 visually. Subjects were tested in two separate $1 / 2-\mathrm{h}$ sessions, with a $1 / 2-\mathrm{h}$ break between sessions, and list modality was blocked by sessions, such that half the subjects had auditory lists in the first session and half had visual ones. Within each session, half the lists were followed by "end" instructions, and half by "beginning" instructions. The ordering of these instructions with respect to lists was determined randomly, but with the additional constraint that no more than three consecutive lists were followed by the same instruction. Before and after the presentation of each list word, subjects had to copy down a sequence of five three-digit numbers. The numbers were spoken in the same voice, in the same manner, and at the same rate as the words. List words, distractor materials, and the ordering of instructions were all balanced or rotated across other experimental conditions.

\section{Materials and Procedure}

By sampling randomly without replacement, four different sets of 20 lists of six words were constructed from a pool of 480 common, two-syllable nouns. Sufficient batches of five threedigit numbers were taken from random-number tables to put together with these word sets such that each word was preceded and followed by one batch of numbers. Two recordings of each of the four sets of word lists and the associated numbers were made. Two videorecorders were used to record "auditory" and "visual" tapes simultaneously. This was done in the following way. One of the two recorders had the video channel permanently switched off and so this recorded the auditory lists (the experimenter read aloud the list words as well as the distractor digits). The second recorder was also programmed to record the distractor digits, but at each word presentation the sound channel was switched off. At the same time, a camera was automatically switched on to record through the video channel a printed representation of the appropriate word: for this, each word was simply displayed on a card in front of the camera. A Commodore PET microcomputer was programmed to control switching from sound to video channels and to control the timing of distractor and word sequences by displaying warning lights for the experimenter while the recording was in progress. Great care was taken, in making the recording, to ensure that the recorded list and distractor items were all spoken in a regular and even manner, with pitch, stress, and tone as similar as possible. For the subsequent benefit of the subjects, bleeps were also recorded at certain points during the sequence.

For any one list, the sequence of events was as follows. First, a bleep was recorded, as a warning signal for the subjects, and there was then a 2-sec unfilled interval before the first of the five three-digit numbers was recorded. These numbers were recorded regularly at the rate of one triad every 2 -sec period that elapsed, and, during the same interval after the fifth triad, another bleep was recorded, this one to signal the onset of a word presentation. At the same instant, the visual presentation of a word was recorded on the videotape, with the duration of the word lasting a full $2-\mathrm{sec}$ interval. The auditory presentation of the same word was taped on the other recorder during the same 2 -sec period, but it was spoken so as to occur more or less during the middle of the period, that is, in rhythm with each three-digit number. Within the next 2-sec period, the first of the next batch of three-digit numbers was recorded, and so on to the end of the list. At the end of a list, within the 2-sec period directly following that in which the last numbers were presented, a general recall instruction was recorded. For auditory lists, this signal consisted of the experimenter's saying "recall"; for visual lists, a diagonal line across the screen was recorded. Two additional tapes were recorded, each one having a single practice list for each modality of presentation. All subjects received the same practice lists at the beginning of the appropriate testing session.

All the subjects first read detailed, typewritten instruction sheets, which were then supplemented orally by the experimenter. They were informed that the experiment involved two separate but equally important tasks, a copying task and a memory task. They were given recall booklets with one page for each list, each page containing seven columns of five lines to be used to write down the numbers in the copying task. Each page also contained a space labeled "words recalled." The importance of accurately copying down the numbers was stressed, and the subjects' performance of this task was carefully and manifestly monitored by the experimenter. The subjects were also told to focus on each word presentation only during its occurrence and to try not to think about the words in any way while they were copying down the numbers.

Lastly, the subjects were of course told that, in addition to the general, recorded recall signal, they would, at the end of each list, be given particular recall instructions by the experimenter; the experimenter would at that time say either "end" or "begin ning." They were told that these instructions meant, respectively, that they should start by writing down any words they could remember from the second or from the first part of the list, and only then to go on to write down any other words that they could still remember. They were told that, in both cases, they could 
write the words in any order they liked, so long as they gave priority in recall as instructed. Recall of each list typically took about half a minute or so.

\section{RESULTS}

The recall data, summarized in Figure 1, appear to show a pronounced auditory advantage in recall of recency items and, moreover, an advantage that does not seem much affected by recall instructions, despite the marked effect of those instructions upon the level of recall of recency items generally. This description of the data was well supported statistically by the results of an overall analysis of variance of individual subject recall scores. The serial position effect was significant $[F(5,150)=22.09, \mathrm{MSe}=1.17, \mathrm{p}<.001]$. Recall was superior with auditory presentation $[\mathrm{F}(1,30)=7.04$, MSe $=1.50, \mathrm{p}<.01]$ and also with "end" instructions $[F(1,30)=5.03$, MSe $=1.13, p<.05]$. Significant interactions involving serial position indicated that the auditory advantage was localized over the later serial positions $[\mathrm{F}(5,140)=5.40, \mathrm{MSe}=1.10, \mathrm{p}<.001]$, and that so was the effect of instructions $[F(5,140)=$ $4.13, \mathrm{MSe}=0.95, \mathrm{p}<.001]$. There was also a significant interaction between instructions and modality $[\mathrm{F}(1,30)$ $=4.93, \mathrm{MSe}=0.61, \mathrm{p}<.05]:$ The superiority in recall with "end" instructions was confined largely to auditory lists. Although the three-way interaction was not significant, Figure 1 shows that that interaction was due to differences in prerecency, not in recency, recall. The magnitude of the modality difference in recency recall was essentially unchanged.

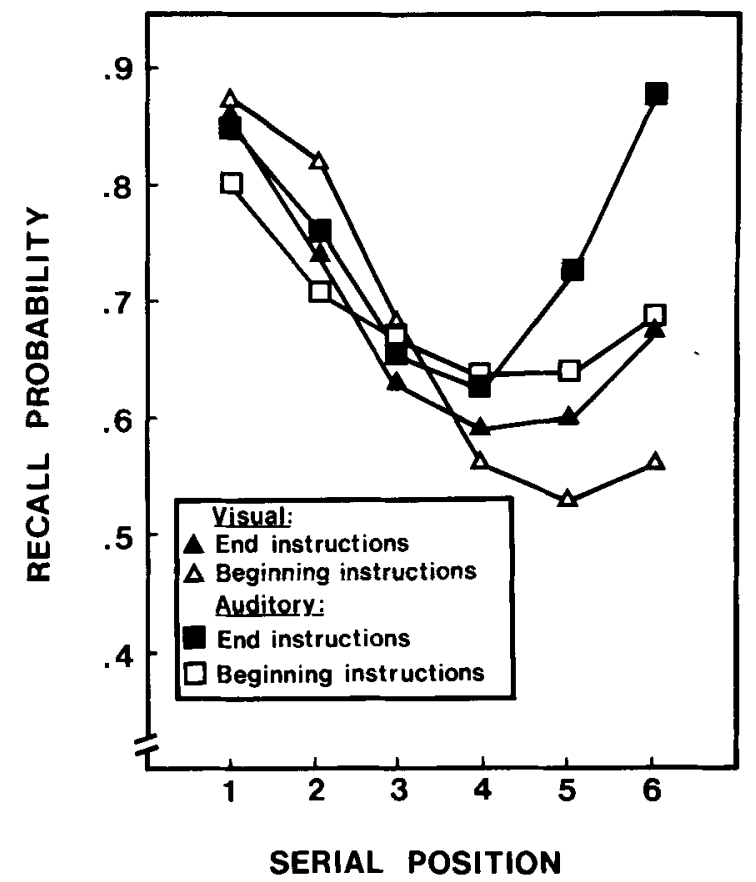

Figure 1. Probability of recall as a function of presentation modality and recall instructions.

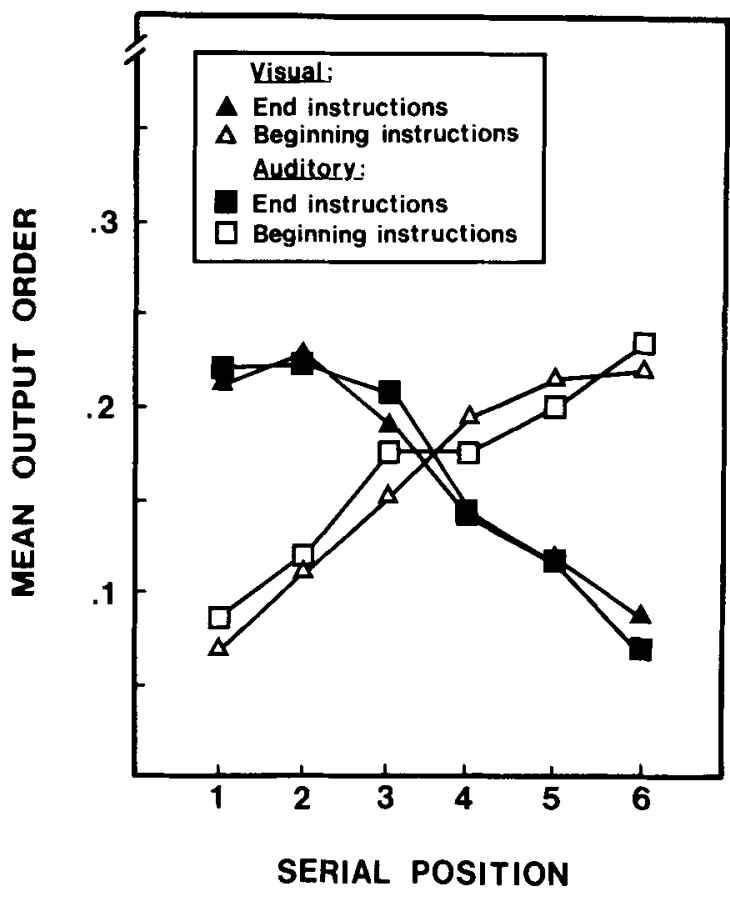

Figure 2. Mean output order as a function of presentation modality and recall instructions.

Because the existence of differences in the overall level of recall may itself lead to differences in outputorder measures, order-of-recall data were analyzed using a normalization procedure, according to which the mean output position of items recalled from each serial position was proportionalized on the mean total in each condition. These data are summarized in Figure 2. It is apparent that subjects complied well with the recall instructions. Moreover, there seems to be little indication that the pattern of recall order was affected by modality. These conclusions were well supported statistically by the results of an overall analysis of variance which, in order to use more reasonable estimates of output-order distributions, was carried out on macrosubject scores obtained by collapsing data over every four successively tested subjects. The interaction between instructions and serial position was highly significant $[\mathrm{F}(5,35)=228.67, \mathrm{MSe}=0.0005, \mathrm{p}<.001]$. The serial-position effect was also significant $[F(5,35)=$ $7.43, \mathrm{MSe}=0.0005, \mathrm{p}<.001]$. A similar analysis of the raw output-order data gave comparable results.

\section{DISCUSSION}

It is clear that the auditory advantage observed in previous similar experiments (Gardiner \& Gregg, 1979) is readily obtained under the much more rigorous conditions of the present experiment. It is of some importance to have shown: that the effect does not depend critically on subject vocalization of a self-paced distractor task; that it occurs when both list and distractor items are spoken in a regular and even manner by the experi- 
menter; and that it does not depend in any simple way on recall order. The experiment also showed that the effect was quite definitely not enhanced by recalling prerecency items first. This outcome contrasts strongly with that from immediate-recall studies (Craik, 1969; Madigan, 1971 ; see too Nilsson et al., 1979).

Instructions to give priority in recall to the beginning of the list did, however reduce recency recall generally, as had been found in previous studies-excepting an experiment in this very distractor paradigm described by Whitten (1978). Whitten, however, had presented 18-word lists and in word-doubles rather than one at a time. And although his analysis revealed no effect of instructions, his data do show that recall of the last word-double in a list was about $20 \%$ lower with "beginning" than with "end" instructions-a reduction of a similar order of magnitude to that observed in our data. There was also an interaction between instructions and modality, but this apparently came about because in the visual, but not in the auditory, modality, our data replicate an observation made by Dalezman (1976). In a delayed-recall test, he too found that similar recall instructions increased recall of first-recalled items but correspondingly reduced recall of later-recalled items, thus leaving overall recall unchanged. This was not so in the auditory modality, where our data show that recall of prerecency items was not reduced by recalling recency items first. This cannot be related to modality differences in the outputorder data, and it seems possible that greater susceptibility of visual items to output interference may have contributed to this slightly complex pattern of results (Madigan, 1971; Nilsson et al., 1979).

Perhaps the most interesting finding is that the auditory advantage in longer term recall has now been shown not only to be not removed by subsequent auditory input, but also to be not enhanced by starting recall from the beginning of the list. Moreover, we present evidence in a forthcoming study that, at least under certain conditions, the effect is not eliminated or even reduced by phonological similarity among list items (Gregg \& Gardiner, in press). With respect to none of these variables does the effect seem to correspond functionally with the auditory advantage in immediate recall. By the same token, we have found little evidence in this paradigm of any dissociation between auditory and visual recency. This is consistent with the possibility that whatever gives rise to recency recall here may also be partly responsible for the auditory recency advantage. In particular, we had previously speculated that the auditory advantage in longer term recall might simply reflect greater temporal distinctiveness in the auditory mode (Gardiner \& Gregg, 1979). This conjecture accords well with the view that recency itself is due to a backwardscanning retrieval strategy which utilizes ordinal retrieval cues (e.g., Bjork \& Whitten, 1974; Glenberg, Bradley, Stevenson, Kraus, Tkachuk, Gretz, Fish, \& Turpin, 1980; Glenberg \& Kraus, 1981). And we note that, although their theory does not explain them, our findings in this paradigm generally lend quite good support to a two-process theory of the sort proposed by Glenberg et al. (1980) to account for long-term serial position effects.

Evidence of a somewhat different auditory advantage in longer term recall does not, of course, necessarily mean that this effect might not be integrated with other modality differences in recency recall in some quite general theory. Considered more broadly, a temporaldistinctiveness hypothesis fits nicely with some other evidence-including evidence that the auditory mode is indeed more specialized for temporal processing (Metcalfe, Glavanov, \& Murdock, 1981)-and Gardiner (1983) has argued that it may provide one such possibility; other similarly broad hypotheses have been proposed recently by Campbell and Dodd (1980) and by Shand and Klima (1981) in connection, respectively, with recency advantages obtained with lipreading and with sign language in immediate recall. If a theory that accounts for both the immediate and the longer term auditory advantage is to be viable, then some satisfactory resolution of apparent differences between those effects has to be achieved. This remains feasible. In the present case, for instance, it is possible that the finding of an enhanced auditory advantage in immediate recall when recall starts from the beginning of the list might be due largely to the presence of a ceiling effect when recall starts from the end of the list, and hence be of little theoretical significance (for further discussion, see Gardiner, 1983).

Be that as it may, the present, empirically motivated study strengthens the conclusion that the auditory advantage in longer term recall cannot be explained in terms of an echoic memory interpretation. ${ }^{1}$ Moreover, it demonstrates an additional difference in the nature of the effect in this paradigm compared with that observed in immediate recall. But it leaves the question of the relation between immediate and longer term effects quite open. Although the evidence distinguishing between the two effects suggests that they may require some degree of theoretical separation, it does not compel that conclusion.

\section{REFERENCES}

Bjork, R. A., \& Whitren, W. B. Recency-sensitive retrieval processes in long-term free-recall. Cognitive Psychology, 1974, 6, 173-189.

Brondeent, D. E., Vine8, R., \& Brondeent, M. H. P. Recency effects in memory, as a function of modality of intervening events. Psychological Research, 1978, 40, 5-13.

CAmpbeld, R., \& DodD, B. Hearing by eye. Quarterly Journal of Experimental Psychology, 1980, 32, 85-99.

Craix, F. I. M. Modality effects in short-term storage. Journal of Verbal Learning and Verbal Behavior, 1969, 8, 658-664.

Crowder, R. G. Principles of learning and memory. Hillsdale, N.J: Erlbaum, 1976.

Crowder, R. G., \& Morton, J. Precategorical acoustic storage (PAS). Perception \& Psychophysics, 1969, 5, 365-373.

Dalezman, J. J. Effects of output order in immediate, delayed, 
and final recall performance. Journal of Experimental Psychology: Human Learning and Memory, 1976, 2, 597-608.

Gardiner, J. M. On recency and echoic memory. Philosophical Transactions of the Royal Society London, B, 1983, 302, 267-282.

Gardiner, J. M., Gathercole, S. E., \& Gregg, V. H. Further evidence of interference between lipreading and auditory recency. Journal of Experimental Psychology: Learning, Memory and Cognition, 1983, 9, 328-333.

Gardine R, J. M., \& GregG, V. H. When auditory memory is not overwritten. Journal of Verbal Learning and Verbal Behavior, $1979,18,705-719$.

Gardiner, J. M., Thompson, C. P., \& Maskarinec, A. S. Negative recency in initial free recall. Journal of Experimental Psychology, 1974, 103, 71-78.

Glenberg, A. M., Bradley, M. M., Stevenson, J. A., Kraus, T. A., TKachuk, M. J., Gretz, A. L., Fish, J. H., \& Turpin, B. A. M. A two-process account of long-term serial position effects. Journal of Experimental Psychology: Human Learning and Memory, 1980, 6, 355-369.

Glenbero, A. M., \& Kraus, T. A. Long-term recency is not found on a recognition test. Journal of Experimental Psychology: Human Learning and Memory, 1981, 7, 475-479.

Grego, V. H., \& Gardiner, J. M. Phonological similarity and enhanced auditory recency in longer-term free recall. Quarterly Journal of Experimental Psychology, A, in press.

Madigan, S. A. Modality and recall order interactions in shortterm memory for serial order. Journal of Experimental Psychol$o g y, 1971,87,294-296$.

Martin, M., \& Jones, G. V. Modality dependence of loss of recency in free recall. Psychological Research, 1979, 40, 273-289.

Metcalfe, J., Glavanov, D., \& Murdock, M. Spatial and temporal processing in the auditory and visual modalities. Memory \& Cognition, 1981, 9, 351-359.

Nilsson, L. G., Wriaht, E., \& Murdock, B. B., Jr. Order of recall, output interference, and the modality effect. Psychological Research, 1979, 41, 63-78.

Shand, M. A., \& KLima, E. S. Nonauditory suffix effects in congenitally deaf signers of American Sign Language. Journal of Experimental Psychology: Human Learning and Memory, $1981,7,464-474$

Spoenr, K. T., \& Corin, W. J. The stimulus suffix effect as a memory coding phenomenon. Memory \& Cognition, 1978, 6, 583-589.

Tzena, O. J. L. Positive recency in delayed free recall. Journal of Verbal Learning and Verbal Behavior, 1973, 12, 436-439.

Watkins, M. J., Watkins, O. C., \& Crowder, R. G. The modality effect in free and serial recall as a function of phonological similarity. Journal of Verbal Learning and Verbal Behavior, 1974, 13, 430-447.

Watkins, O. C., \& Watkins, M. J. The modality effect and echoic persistence. Journal of Experimental Psychology: General, 1980, 109, 251-278.

WhitTen, W. B. Output interference and long-term serial position effects. Journal of Experimental Psychology: Human Learning and Memory, 1978, 4, 685-692.

\section{NOTE}

1. This was disputed by an anonymous referee who suggested that echoic memory might somehow "sneak through" in this paradigm and be transformed into a more permanent trace during the gap between word and number presentations. In fact we had considered this possibility earlier, in thinking about our original findings (Gardiner \& Gregg, 1979), and we had discounted it for several reasons. It is not only post hoc: it seems implausible. Why does echoic memory not sneak through in the similar gaps between list and distractor items in paradigms where distractors occur just at the end of the list? How might having distractors after every word facilitate the recoding of echoic information?

(Manuscript received December 3, 1982; revision accepted for publication May 27, 1983.) 